\title{
Stimulating preventive procedures in primary care. Effect of PIUPOZ program on the delivery of preventive procedures
}

\author{
Ewelina Gowin ${ }^{1}$, Dirk Avonts ${ }^{2}$, Wanda Horst-Sikorska', Joanna Dytfeld ${ }^{1}$, Michal Michalak ${ }^{1}$
}

1Family Medicine Department, Poznan University of Medical Sciences, Poland
2Family Medicine Department, University of Ghent, Belgium

Submitted: 11 January 2011

Accepted: 11 April 2011

Arch Med Sci 2012; 8, 4: 704-710

DOI: 10.5114/aoms.2012.30294

Copyright @ 2012 Termedia \& Banach

\section{Abstract}

Introduction: Educational meetings are one of the most frequently used strategies to change doctors' professional behavior; however, their effectiveness as a single intervention is limited. This study evaluated the effect of a multifactorial intervention, based on interactive workshops, on the GPs' knowledge and the delivery rates of preventive procedures in primary care.

Material and methods: The study population comprised 106 GPs working in the Wielkopolska region recruited to the PIUPOZ program (Improving Quality in Primary (are). The intervention in the program consisted of lectures, interactive workshops and an audit, before and three months after the training. Trained medical students directly observed GPs to register which of 12 studied preventive procedures were performed during the consultation in patients aged $40+$. Results: A total of 1060 consultations were recorded, during which 4899 preventive procedures were delivered: 2115 before and 2784 after workshops. The mean number of preventive procedures per patient before and after workshops was 3.84 and 5.25 respectively $(p<0.0001)$. The most commonly performed preventive procedures were blood pressure, blood glucose and lipid profile measurement. Mean number of correct answers for 16 questions in the initial knowledge test was 8.7 and 12.7 in the final test $(p<0.0001)$.

Conclusions: The observed number of delivered preventive procedures was below the recommended range. Preventive procedures based on laboratory tests were performed more often than lifestyle counseling.

Key words: primary care, health promotion, preventive procedures.

\section{Introduction}

Effective implementation of prevention improves the global health status of the population and it is well recognized that offering preventive procedures is an essential task in primary care. But recent studies show that the delivery of preventive services in GP (general practitioner) surgeries falls below recommended levels [1, 2]. Several types of intervention are possible to stimulate the preventive behavior of GPs: educational meetings, learning through social influence, quality circles, feedback, prompts and reminders, organizational change, and financial or regulatory interventions [3]. Effectiveness of these approaches is demonstrated in individual situations, but global changes in the delivery of preventive care at a group level are usually small to moderate $[3,4]$.

\author{
Corresponding author: \\ Ewelina Gowin PhD \\ Family Medicine Department \\ Poznan University \\ of Medical Science \\ 49 Przybyszewskiego \\ 60-355 Poznan, Polska \\ Phone: +48 605723017 \\ E-mail: ewego@poczta.onet.pl
}


Educational meetings are one of the most often used strategies; however, their effectiveness as a single intervention is limited [3]. The PIUPOZ program offered a multifactorial intervention, based on interactive workshops in order to increase the delivery rates of preventive procedures in primary care. The acronym PIUPOZ stands for Poprawa lakosci Uslug w Podstawowej Opiece Zdrowotnej (Improving Quality in Primary Care). GPs' knowledge and performance in the field of prevention was examined before and after the educational training. Additionally GPs were invited to answer an anonymous questionnaire regarding their opinions on the PIUPOZ program: the impact of participation in the program on their daily practice, especially offering preventive procedures.

This study evaluated the effect of the PIUPOZ program on the delivery rates of preventive procedures in primary care.

\section{Material and methods}

This study was performed in 2009 as part of the PIUPOZ program carried out since 2007 by the Family Medicine Department of the University of Medical Sciences, Poznan, Poland. The program was funded by the Financial Mechanism of the European Economic Area and Norwegian Financial Mechanism. The program consisted of lectures, interactive workshops and an audit, before and 3 months after the training. Educational meetings were performed in groups of 15 people, and lasted $25 \mathrm{~h}$ during 2 weekends. The main topics were prevention, diagnosis and treatment of the major clinical threats: coronary heart disease (CHD), chronic obstructive pulmonary disease (COPD), breast and colon cancer. Participation, accommodation and course materials were provided free of charge. After completing the course participants received a certificate and 25 educational points.

The study population consisted of GPs who were taking part in the PIUPOZ program in 2009.

Doctors with or during specialization in family medicine or internal medicine working in primary care settings in the Wielkopolska region were invited to take part in the project. Doctors working in academic practices or private practices, which are not paid by the National Health Fund, were excluded from the study. During three years of the PIUPOZ program invitations were sent by mail or email to all 1170 practices in the region. In 2009, 390 practices were contacted. Recruitment to the program was extended by personal contacts at medical conferences or with the aid of adverts in medical press. Candidates were registered by the medical secretary of the Family Medicine Department. Four doctors were excluded due to withdrawal of previous agreement, incomplete surveys, or inability to carry out a second visit.

Observation of the preventive behavior of the GPs was performed directly in the office of the doc- tors. The observers ( 2 men and 2 women) were recruited among final year medical students interested in family medicine who had their own cars to reach all practices even in the countryside. They received $4-h$ training about preventive guidelines, provided by a member of the research team. In addition they were instructed about the study registration form and how to perform an audit, respecting confidentiality. The observers followed the GPS during consultations and observed preventive procedures of 5 consecutive patients aged 40 plus. They registered preventive procedures performed during these 5 consultations (direct observation). In addition, the observers noted preventive acts of the five patients, noted in the medical record during the previous year (retrospective registration). For each GP 10 consultations were registered ( 5 before and 5 after the workshop), while a patient was included only once: at the initial visit, or at the second visit. The selection criteria for patients were their age and agreement for participation. Observers filled in questionnaires for the first five patients meeting these criteria according to the rule first come first served, to minimize selection bias. The registration form of the observers consisted of 12 preventive procedures and is presented in Table I. Identification of the observed physician was not registered on the study form and the observed doctors did not have access to the study forms of the observers. Three months after the initial visit, the same observer visited the GP a second time to perform a similar observation and registration.

The GPs' knowledge was tested with 16 multiple choice questions (5 possible answers, one correct).

\section{Statistical analysis}

Descriptive statistics were used to characterize the observed patients. The analysis focused on the delivery rates of different preventive procedures and the differences between the delivery rates before

Table I. Analyzed preventive procedures

\begin{tabular}{|l|}
\hline Body weight measurement \\
\hline Body mass index \\
\hline Waist measurement \\
\hline Blood pressure \\
\hline Blood glucose \\
\hline Lipid profile \\
\hline Dietary advice about fat \\
\hline Dietary advice about fruits and vegetables \\
\hline Physical activity counseling \\
\hline Family history \\
\hline Tobacco use screening \\
\hline Alcohol drinking screening \\
\hline
\end{tabular}


Table II. Characteristics of the GPs $(n=106)$

\begin{tabular}{|ll|}
\hline Variable & Number (\%) \\
\hline Female & $69(65 \%)$ \\
\hline Male & $37(35 \%)$ \\
\hline Mean age [years] & $45.93( \pm 9.394)$ \\
& $95 \% \mathrm{Cl} 44.16-47.71$ \\
\hline Years in practice & $20.15( \pm 10.298)$ \\
& $95 \% \mathrm{Cl} 17.120-20.816$ \\
\hline Practice type: & $90(85 \%)$ \\
\hline Single-handed & $16(15 \%)$ \\
\hline Location of practice: & $44(42 \%)$ \\
\hline Town > 50 000 inhabitants & $38(36 \%)$ \\
\hline Town < 50 000 inhabitants & $24(22 \%)$ \\
\hline Countryside & \\
\hline
\end{tabular}

and after the program. Chi-square tests were used to compare quantitative data. Chi-square tests were used to compare the delivery rates of preventive procedures for female and male patients. All tests were analyzed at the significance level of $\alpha=0.05$, and analyses were performed using Statistica v. 8.0 (StatSoft Inc, http://www.statsoft.com).

\section{Results}

Of the 139 doctors who agreed to participate, 110 participated in the workshops and 106 were included in the present study. As a result a total of
1060 patients' forms (among 106 GPs) were collected and analyzed: 530 of the initial visit and 530 of the second visit of the observer.

GPs' demographic characteristics, years in practice, practice types and locations are presented in Table II. The observed patients prior to the workshops consisted of 322 women (60.75\%) and 208 men $(39.25 \%)$, and at the second visit 273 women (51.5\%) and 257 men (48.5\%). The mean age in the patient groups before and after the workshop was $56.8 \pm 11.23$ (95\% Cl: 55.82-57.78). Mean age of females was $56.26 \pm 12.030,95 \% \mathrm{Cl}: 55.94-58.58$ (after $57.36 \pm 12.457,95 \% \mathrm{Cl}: 55.89-58.85$ ), males $56.08 \pm 10.713,95 \% \mathrm{Cl}: 54.62-57.55$ (after 56.19 $\pm 11.824,95 \% \mathrm{Cl}: 54.74-57.64)$.

During 1060 registered patient contacts GPs delivered a total of 4899 preventive procedures. The mean number of procedures per patient before and after workshops was $3.84 \pm 2.44$ (95\% Cl: 3.63-4.04) and $5.25 \pm 2.19$ ( $95 \% \mathrm{Cl}: 5.06-5.44)$ respectively. The difference is statistically significant $(p<0.0001)$. Details are presented in Table III.

Before workshops male GPs delivered on average more preventive procedures than female GPs (4.21 vs. 3.64, $p<0.0001$ ). Three months after the PIUPOZ program that difference was no longer observed (5.22 and 5.1). Patients' gender had no effect on delivery rates of preventive procedures.

\section{Knowledge test results}

Mean number of correct answers for 16 questions in the initial test was $8.7 \pm 1.902$ (95\% Cl: 8.2-

Table III. Delivery rates of preventive procedures before and three months after PIUPOZ program

\begin{tabular}{|c|c|c|c|c|c|c|}
\hline \multirow[t]{2}{*}{ Procedure type } & \multicolumn{2}{|c|}{ Before workshops } & \multicolumn{2}{|c|}{$\begin{array}{l}\text { Three months after } \\
\text { PIUPOZ program }\end{array}$} & \multirow[t]{2}{*}{ Change [\%] } & \multirow[t]{2}{*}{ Value of $p$} \\
\hline & $\begin{array}{l}\text { No. of } \\
\text { procedures }\end{array}$ & $\% n$ & $\begin{array}{l}\text { No. of } \\
\text { procedures }\end{array}$ & $\% n$ & & \\
\hline $\begin{array}{l}\text { Body weight } \\
\text { measurement }\end{array}$ & 238 & 44.9 & 389 & 73.4 & 63.44 & $<0.00001$ \\
\hline Waist measurement & 13 & 2.45 & 74 & 13.96 & 469.23 & $<0.00001$ \\
\hline Body mass index & 60 & 11.32 & 78 & 14.72 & 30 & NS \\
\hline Blood pressure & 367 & 69.24 & 453 & 85.47 & 23.43 & $<0.00001$ \\
\hline Blood glucose & 364 & 68.68 & 384 & 72.45 & 5.49 & NS \\
\hline Lipid profile & 267 & 50.38 & 280 & 52.83 & 4.87 & NS \\
\hline Dietary advice about fat & 97 & 18.30 & 151 & 28.49 & 55.67 & 0.00009 \\
\hline $\begin{array}{l}\text { Dietary advice about fruits } \\
\text { and vegetables }\end{array}$ & 190 & 35.85 & 148 & 27.92 & -22.1 & 0.00564 \\
\hline Physical activity counseling & 130 & 24.53 & 282 & 53.21 & 116.92 & $<0.00001$ \\
\hline Family history & 45 & 8.49 & 150 & 28.3 & 233.33 & $<0.00001$ \\
\hline Tobacco use screening & 189 & 35.66 & 274 & 51.7 & 44.97 & $<0.00001$ \\
\hline Alcohol drinking screening & 68 & 12.83 & 121 & 22.83 & 77.94 & 0.00002 \\
\hline Total & \multicolumn{2}{|c|}{2115} & \multicolumn{2}{|c|}{2784} & & \\
\hline
\end{tabular}


Table IV. The effect of the PIUPOZ program on the delivery rates of preventive procedures in primary care - GPs' opinions

\begin{tabular}{|lcccccc|}
\hline Procedure type & \multicolumn{7}{c|}{ Change in frequency of performed procedures } \\
\cline { 2 - 7 } & Increase & $\%$ & Decrease & $\%$ & No change & $\%$ \\
\hline Body weight measurement & 70 & 66.04 & 0 & 0 & 36 & 33.96 \\
\hline Waist measurement & 68 & 64.55 & 0 & 0 & 38 & 35.45 \\
\hline Body mass index & 77 & 72.64 & 0 & 0 & 29 & 27.36 \\
\hline Blood pressure & 44 & 41.50 & 0 & 0 & 62 & 58.5 \\
\hline Blood glucose & 59 & 55.66 & 0 & 0 & 47 & 44.34 \\
\hline Lipid profile & 62 & 58.49 & 2 & 1.89 & 42 & 39.62 \\
\hline Dietary advice about fat & 78 & 73.58 & 0 & 0 & 28 & 26.42 \\
\hline $\begin{array}{l}\text { Dietary advice about fruits } \\
\text { and vegetables }\end{array}$ & 76 & 71.7 & 2 & 1.89 & 30 & 28.3 \\
\hline Physical activity counseling & 75 & 70.75 & 0 & 0 & 31 & 29.25 \\
\hline Family history & 85 & 80.19 & 0 & 0 & 21 & 19.81 \\
\hline Tobacco use screening & 64 & 60.38 & 0 & 0 & 42 & 39.62 \\
\hline Alcohol drinking screening & 83 & 78.30 & 0 & 0 & 23 & 21.70 \\
\hline
\end{tabular}

9.2) (correct answers for $55 \%$ of questions). In the final test mean number of correct answers was 12.7 \pm 2.120 (95\% Cl: $11.9-13.4)$ (79\% of correct answers). The difference is statistically significant $(p<0.0001)$.

\section{GPs' opinions on the impact of the PIUPOZ program on their daily practice}

Most of the doctors (66.15\%) agreed that workshops performed during the PIUPOZ program increased the number of performed preventive procedures; $70 \%$ declared they had sufficient skills to carry out preventive measures. Detailed analysis in the different preventive fields of the course is presented in Table IV.

\section{Discussion}

Participation in an interactive workshop in preventive medicine increased the knowledge and the delivery rates of preventive procedures in the observed primary care practices. At the baseline, rates of patients receiving preventive procedures varied from $2.45 \%$ for waist circumference measurement to $69.24 \%$ in the case of blood pressure measurement. After the PIUPOZ program these rates increased to $3.36 \%$ and $85.47 \%$, respectively. The most commonly performed procedures (before and after the training) were blood pressure, blood glucose and lipid profile measurement. After the program, the delivery rate of eight procedures increased and that of one procedure decreased.

In general in our study preventive procedures based on laboratory tests were performed more often than lifestyle counseling. But the effect of the training was more prominent on lifestyle counseling.

The observed overall delivery of preventive procedures in primary care falls below the levels recommended by the Polish Ministry of Health, which suggests offering preventive procedures concerning physical activity, alcohol consumption, tobacco use, food intake, body weight and measuring glucose and lipid levels in blood to all patients above 40 years of age on an annual basis. Deprivation of preventive procedures in primary care is not a phenomenon unique to Poland. The situation is similar in other countries. It is estimated that family doctors in various countries perform on average about $30 \%$ of the recommended procedures [5-7]. According to American, European, Australian and WHO (World Health Organization) guidelines a number of specific preventive activities should be offered to all adult patients: screening for alcohol and tobacco use, measuring weight, height and waist circumference and calculating body mass index (BMI), blood pressure measurement, and diet and physical activity counseling [8-15].

Educational courses for medical health care workers are commonly used to increase preventive activities. Many studies have shown only a small impact of training on doctors and a significant discrepancy between actually delivered and recommended preventive procedures [16-19]. Effectiveness is primarily dependent on the form of training [20]. Lectures indeed contribute to enhancing knowledge of participants, but do not affect the percentage of provided preventive activities [21]. By contrast, interventions based on interactive sessions in small groups, enabling exercise practical 
skills, have a positive influence on physicians [16]. Activities comprising at least a few elements are considered as more effective $[6,20]$. Practice-oriented continuing education, combined with process improvement methods, may improve systems for delivery of prevention in primary care [22].

Visit of an observer in practice was a form of audit. In Poland there is no system evaluating physicians' work. Awareness of being observed may have had a beneficial influence on GPs. It has been shown that an audit may increase the rate of delivered preventive services [23].

The main result of participation in the courses was not the knowledge gained, but the change in behavior. Therefore, the increased percentage of preventive procedures noted by observers during the second visit (after the training) may be considered as an indicator of the project's effectiveness. Participation in the program resulted in a statistically significant increase in the number of performed preventive procedures $(p<0.0001)$. It rose by $32 \%$. Such a percentage change is considered in the literature as a relevant one [20]. Delivery of eight out of twelve procedures increased significantly. The commonest procedures performed both before and after the course were blood pressure, blood glucose, and lipid profile measurements. A question about the fruit content in diet was the only procedure which was lower in the provision in observations made during the second visit compared to the baseline situation. One reason may be lack of time. Doctors were to decide specifically which preventive activities should be done during the visit. Raising awareness in this regard was likely to result in earmarking specific time for certain activities and limiting it for the less important ones. Based on the literature it is known that the more procedures are recommended during one consultation, the fewer prophylactic measures are provided [24]. Nutrition counseling is relatively low in the hierarchy [25].

To be effective any intervention must meet a number of conditions. The basic requirement is the active involvement of participants and a willingness to change. Physicians showed such readiness by application to the program and then through their attendance. The success of the program may be explained by the complexity of activities used. It is known that there is considerable discrepancy between theoretical knowledge and its application in practice, which is why the PIUPOZ program was primarily designed to teach practical skills [2]. The effect of training was reinforced through interactive workshops.

Events such as conferences and workshops often require a significant financial effort. In order to reduce costs they are often sponsored by pharmaceutical companies. Thus, they are mainly concerned with treatment, and promote the company and its products, while the topic of prevention is rarely discussed. During studying, the training of doctors is focused mainly on therapy rather than prevention of diseases. Therefore, the PIUPOZ program gave doctors a good opportunity to expand their knowledge on health prevention. Workshops in small groups contributed to better contact between the participants and created an opportunity to exchange experiences, especially valuable for GPs working in single practices. Through courses doctors had the opportunity to foster cooperation and get support in a group of people who face similar problems everyday at work. Moreover, the interval between two parts of the training allowed gradual introduction of knowledge into practice. The training was carried out during weekends, in favorable recreational conditions, when doctors were separated from everyday activities. All of this contributed to better assimilation of knowledge. Effects of participation in the program on the number of preventive services has been confirmed not only in our observation, but also subjectively by GPs. In their opinion the training has increased the number of procedures performed in practice. Most doctors were positive about the impact of the program in their daily work and expressed a wish to participate in similar training in the future. When asked, GPs reported increased delivery of the procedures discussed at the course.

Knowledge test results clearly showed an increase of knowledge, which was due to training. Before participating in PIUPOZ male doctors provided more prevention services when compared to female ones. After the training such a difference was not found. One may, therefore, conclude that participation in the program to a greater extent improved the quality of services provided by female doctors.

Difficulties in comparing the results of the PIUPOZ program to literature data derive from different organization of health care systems in different countries [26]. Most similar to the Polish system is the British one. Differences between studies are also dependent on research methods. When medical records or patients' opinions are used, there is a risk of unreliable data $[26,27]$. Doctors do not record all provided advice. In the case of laboratory tests, however, results are usually entered in the medical records. Relying on patients' judgment can also lead to a low number of actual benefits provided. Patients often do not remember or cannot indicate which prophylactic procedures they received. On the other hand, relying on surveys completed by the doctors carries a risk of overestimation. Doctors aware of the necessity of prophylaxis may have a tendency to overstate the benefits provided $[28,29]$. The most reliable are videos of the consultation process. Unfortunately, they are difficult to accept by both physicians and patients. 
Thus, none of the research methods is perfect [26]. Presence of a witness in the form of a medical student allows the reality of the consultation process to be observed as closely as possible.

In our study most doctors worked in group practices located in towns, which is characteristic of Polish primary care practices. The practices are paid on a capitation basis according to the size of the patient list (between 2500 and 2750). For organizational and economic reasons it is more convenient to work in group practices taking care of a large population. Village practices are in the minority.

A specific value of the present study is the direct observation of doctors' preventive behavior by trained observers. Many estimates on the delivery of preventive procedures are based on doctors' self records or on patients' medical records. The latter can be easily performed in the case of electronic records. In Poland electronic patient records are not common. Direct observation of the doctor and inspection of the patient record seems to be the most appropriate way to study the doctor's behavior in real life.

There are some weak points in our study. The study sample was not randomly selected, but based on active recruitment of interested volunteers for the offered training program. In the first year of the project we attempted to obtain a statistically representative sample by inviting physicians selected from the NHF database. Unfortunately, despite the best efforts of the organizers, this resulted in a very poor turnout. That is why in subsequent years recruitment for the program was done on the basis of voluntary reports. This bias might have resulted in selection of GPs who are more interested in prevention. The real preventive performance of an average Polish GP may be worse than in the present study. However, even taking into account this bias, preventive service in our study sample is probably still suboptimal, since the workshops lead to significant improvement.

The results may help to select the most effective continuing educational activities. This will be very important for health professionals while planning which meetings to choose and for organizers to consider strategies to plan the most effective intervention.

Continuing medical education meetings may be effective in increasing GPs' knowledge about preventive medicine. In order to achieve the desired increase in the rate of delivered preventive procedures it is necessary to meet several conditions. First of all, the will of doctors to make changes is required. Second, they should acquire both necessary knowledge and practical skills. What is more, the skills should be performed properly in their daily practice. That is why both training and commitment of the participants are so important. There- fore multifactorial intervention based on interactive courses aimed at doctors willing to make changes can help to improve the quality of prevention services in primary care.

In conclusion, the observed number of preventive procedures delivered in primary care surgeries in the Wielkopolska region was below the recommended range. Preventive procedures based on laboratory tests were performed more often than lifestyle counseling.

\section{Acknowledgments}

All the authors confirm that in the past five years we have not received any reimbursements, fees, funding, or salary from an organization that may in any way gain or lose financially from the publication of this manuscript, either now or in the future. We do not hold any stocks or shares in an organization that may in any way gain or lose financially from the publication of this manuscript, either now or in the future.

We do not hold and we are not currently applying for any patents relating to the content of the manuscript. We have not received reimbursements, fees, funding, or salary from an organization that holds or has applied for patents relating to the content of the manuscript. We have no financial competing interests.

Ewelina Gowin conceived of the study, and participated in its design and coordination. Joanna Dytfeld helped to draft the manuscript. Wanda HorstSikorska participated in the design of the study. Michal Michalak performed the statistical analysis. All authors read and approved the final manuscript.

\section{References}

1. Flocke SA, Stange KC, Goodwin MA. Patient and visit characteristics associated with opportunistic preventive services delivery. J Fam Pract 1998; 47: 202-8.

2. Brotons C, Bjorkelund C, Bulc M, et al. Prevention and health promotion in clinical practice: the views of general practitioners in Europe. Prev Med 2005; 40: 595-601.

3. Hulscher MEJL, Asheden R, Silagy C, Weller D. A systematic review of the effectiveness of promoting lifestyle change in general practice. Family Practice 1997; 14: 160-75.

4. Cabana MD, Rand CS, Powe NR, et al. Why don't physicians follow clinical practice guidelines? A framework for improvement. JAMA 1999; 282: 1458-65.

5. Ma J, Urizar GG, Alehegn T, Stafford RS. Diet and physical activity counseling during ambulatory care visits in the United States. Prev Med 2004; 39: 815-22.

6. Nelson DE, Bland S, Powell-Griner E, et al. State trends in health risk factors and receipt of clinical preventive services among US adults during the 1990s. JAMA 2002; 287: 2659-67.

7. Steptoe A, Doherty S, Kendrick T, Rink E, Hilton S. Attitudes to cardiovascular health promotion among GPs and practice nurses. Fam Prac 1999; 16: 158-63.

8. Cybulska B, Adamus J, Bejanrowicz J. Profilaktyka choroby niedokrwiennej serca. Rekomendacje Komisji Profi- 
laktyki Polskiego Towarzystwa Kardiologicznego. Kardiol Pol 2000; 53: 4-48.

9. DeBacker G, Ambrosini E, Borch-Johnsen K, et al. Third Joint Task Force Of European and other Societes on Cardiovascular Disease Prevention in Clinical Practice. European guidelines on cardiovascular disease prevention in clinical practice. Eur Heart J 2003; 24: 1601-10.

10. National Institute for Health and Clinical Excellence (NICE) Clinical Guideline CG 43 Obesity; 2006. Avaliable from http://www.nice.org.uk/nicemedia/pdf/CG43quickrefguide2.pdf

11. The Royal Australian College of General Practitioners 'Red Book' Taskforce Guidelines for preventive activities in general practice (7th edition). Melbourne 2009: Available from: http://www.racgp.org.au/Content/NavigationMenu /ClinicalResources/RACGPGuidelines/TheRedBook/redbook 7th edition May 2009.pdf

12. The World Health Organization Report: Prevention of cardiovascular disease. Geneva, 2007. Available from: http://www.who.int/cardiovascular_diseases/guidelines/ PocketGL.ENGLISH.AFR-D-E.rev1.pdf

13. Forum Profilaktyki. Available from: http://www.pfp.edu.pl.

14. American Academy of Family Physicians AAFP Summary of Recommendations for Clinical Preventive Services, AAFP Policy Action November 1996, June 2010 Order No. 1968. Available from:http://www.aafp.org/online/etc/medialib/ aafp org/documents/clinical/CPS/rcps082005.Par.0001.File.tmp/01202010CPS.pdf.

15. Smith S, Jackson R, Pearson T, et al. Principles for National and Regional Guidelines on Cardiovascular DISEASE Prevention: A scientific Statement From the World Heart and Stroke Forum. Circulation 2004; 109: 3112-21.

16. Davis D, Thomson O'Brien MA, et al. Impact of formal continuing medical education: do conferences, workshops, rounds, and other traditional continuing education activities change physician behavior or health care outcomes? JAMA 1999; 282: 867-74.

17. O'Neil KM, Addrizzo-Harris DJ. Continuing medical education effect on physician knowledge application and psychomotor skills. Effectiveness of continuing medication education: American College of Chest Physicians evidencebased educational guidelines. Chest 2009; 135: 37-41.

18. Ramezani MA, Dastanpour M, Eshaghi S, Fadee-Nobari R. Determinants of awareness, treatment and control of hypertension in Isfahan, Central Iran. Arch Med Sci 2009; 4: 1-8.

19. Bero LA, Grilli R, Grimshaw JM, et al. Getting research findings into practice: Closing the gap between research and practice: an overview of systematic reviews of interventions to promote the implementation of research findings. BMJ 1998; 317: 465

20. O'Brien MA, Freemantle N, Oxman AD, Wolf F, Davis DA, Herrin J. Continuing education meetings and workshops: effects on professional practice and health care outcomes. Cochrane Database Syst Rev 2008; 4. Available from: www.thecochranelibrary.com/

21. Thomson, O'Brien MA, Freemantle N, et al. Continuing education meetings and workshops: effects on professional practice and health care outcomes. Cochrane Database Syst Rev 2008; 4. Available from: http://www. thecochranelibrary.com

22. Grimshaw JM, Thomas RE, MacLennan G, et al. Effectiveness and efficiency of guideline dissemination and implementation strategies. Health Technol Assess 2004 8(6).

23. Balas E, Weingarten S, Garb CT, Blumenthal D, Boren SA, Brown GD. Improving preventive care by prompting physicians. Arch Intern Med 2000; 160: 301-8.
24. Godycki-Ćwirko M, Koziarska-Rosciszewska M, Kosiek K. The delivery of prevention programmes for cardiovascular disease and chronic obstructive pulmonary disease in Lodz by primary care physicians. Arch Med Sci 2010; 6: 208-13.

25. Maciosek MV, Coffield AB, Ashley, Edwards NM, Flottemesch TJ. Priorities among effective clinical preventive services results of a systematic review and analysis. Am J Prev Med 2006; 31: 52-61.

26. Doran T, Fullwood C, Gravelle H, et al. Pay-for performance programs in family practices in the United Kingdom. N Engl J Med 2006; 355: 375-84.

27. Dresselhaus TR, Peabody JW. Measuring compliance with preventive care guidelines standardized patients, clinical vignettes, and the medical record. JGIM 2000; 15: 782-8.

28. Dubey V, Mathew R, Iglar K, Moineddin R, Glazier R. Improving preventive service delivery at adult complete health check-ups: the Preventive health Evidence-based Recommendation Form (PERFORM) cluster randomized controlled trial. BMC Family Practice 2006; 7: 44.

29. Mirand AL, Beehler GP, Kuo CL, Mahoney MC. Explaining the de-prioritization of primary prevention: physicians' perceptions of their role in the delivery of primary care. BMC Public Health 2003; 3: 15. 